\title{
Context, meaning, and interpretation, in a practical approach to linguistics
}

\author{
Arie Verhagen
}

In discussions of the relation between language use and context, it is often assumed or impled that meaning may vary with the context-of-utterance It can be argued, however, that this must be a misconception lingulstic meanings must be taken as general, maintaining their identity in different contexts Section 2 provides arguments for this position, from the perspective that formulations of meanings are to function, in a non-circular way, in analyses of actual instances of language use (whether for evaluative or descriptive purposes)

On the other hand, it is argued in section 3 on partly simular grounds that lingulstic meanings are context-dependent in the sense that they contain 'open places' which can only be filled in actual contexts Therefore the (constant, general) meaning of linguistic elements never exhausts the interpretation of actual usage events

As a consequence, the relation between meanings and interpretations cannot be such that the former are 'bullding blocks' of the latter Rather, meanings have to be taken as constraints on interpretations For processes of interpretation, features of the context-of-utterance (whether ttself linguistic or not) can equally be taken as constraints on interpretation, working in parallel with the linguistic features of the utterance, which suggests a view of utteranceinterpretation as a constraint satıfaction process (section 4)

"The theoretical notion of the context-of-utterance is based of course upon a pre-theoretical notion of context [ ] to which we constantly appeal in the everyday use of language Asked by a child or a forergner what a particular word means, we are frequently unable to answer his question without first getting him to supply some information about the context in which he has encountered the word in question We will also say, pre-theoretically, that a certain lexeme, expression or utterance is appropriate or inappropriate, or that it is more or less effective than another, in a certain context The problem is to explicate this pre-theoretical, intuitive, notion of context in a theoretically satısfying way" (Lyons 1977 572) 


\section{Introduction ${ }^{\star}$}

John Lyons' first example quoted above for 1llustratıng that we constantly appeal to the notion of context in our everyday use of language, suggests that meaning is often, if not always, context-dependent we are in general unable to explicate what a word means without referring to some context of use However, the second example suggests precisely the opposite, that is, meaning is context-independent For claiming that a certain expression is (in)appropriate in some context seems to require that we know what it means independently of this particular context of use So, as Lyons in fact points out at the very beginning of the first volume of Semantics, 'meaning' is also a pre-theoretical notion in need of explication What is more, it seems that both explications will have to be interdependent Lyons' 1llustrations of how 'context' is used in everyday language reveal a paradox, its resolution requires that we continuously balance explications of 'context' and 'meaning' with respect to their consequences for each other '

It is this paradox that constitutes the topic of this paper More precisely, the problem is that each of the following statements seems to claim "what a word means", each seems to make perfect sense on its own, but together they imply a contradiction

I Here the word $X$ means $\mathrm{A}$, but there it does not mean $\mathrm{A}$, but rather $\mathrm{B}$

II Since the word $X$ means $A$, it can/cannot be used in this context

An example of I might be

I' In He hasn t reached Utrecht yet, the word yet means "by now" (Dutch translation nog French translation deja), but in Yet he hasn t reached Utrecht, it means 'contrary to expectations" (Dutch translation toch, French translation quand meme)

And an example of II might be

II' Since the word yet means (something like) "There is a rule or regularity according to which an implicit proposition $\mathrm{p}$ evoked by this utterance would normally be true at the time of the utterance, but $p$ is not established as true in this case", it is naturally used in questions, negatives, and other contrast-evoking clauses, but not in simple positive assertives

It will be obvious that in these statements, different things are meant by the phrase "the word yet means X" The exact reason why they are contradictory need not be obvious, though The point seems to be the following Statements of type I all say,

I would like to thank Leo Lentz for useful comments on a previous version of this paper, and Henk Pander Maat for stımulating discussions on the ideas contained in it Naturally, the responsibility for all of it remains completely my own 
in one way or another, that meaning may vary with contexts. Type II statements, on the other hand, all presuppose a definable meaning that remains constant in divergent contexts; for a type II statement to go through it must be assumed that $X$ preserves its meaning $\mathrm{A}$ across contexts. This presupposition, however, contradicts the other statement.

Now in view of specific examples like I' and II', one way to proceed might be to take the issue as an empirical one, for example as the issue of determining both the factors that influence, and those that limit variability, so that I' and II' can both be taken as true, without contradiction. However, I hope to show that it may also be useful not to take off into empirical research immediately, and wonder whether (part of) the issue might not already be resolved by looking carefully how we use our terms and concepts in these statements, examining potential inconsistencies. We may note, for example, that both I and II contain the phrase " $X$ means A", and that this at least suggests that what goes into the slots for $X$ and $\mathrm{A}$ are the same kind of things in both cases, but that this may actually not be the case when the use of such statements is considered more carefully.

One additional reason for taking this course is that in the empirical approach, much depends on the way meanings and contexts are formulated. As the examples I and II already show, certain choices in such formulations will naturally favor one type of statement over the other, thus begging the question how the two notions should actually be related. In other words: in order for an empirical clarification of the issue to be relevant, some conceptual clarification of what we mean by "meaning" and "context" is needed anyhow.

Conceptual clarification is to be guided by considerations of consistency, usefulness for theory formulation, and the like. However, we need some idea of the purposes of the conceptual framework to evaluate usefulness in this sense. Here, much depends on very general views on the nature of science, on the status of theories, what counts as serious problems, etcetera. In what follows, I adopt an instrumental view of language sciences, in the sense that they may be evaluated for their capacity to contribute to the solution of problems external to linguistics proper, such as the interpretation of texts, the construction of dictionaries, translation, language teaching, etcetera. ${ }^{2}$ In general, I will discuss the role of the concepts "meaning" and "context" from two perspectives: first, the perspective of evaluating the quality of instances of language use and designing advice on proper usage; second, that of 'simply' describing language use. As will become apparent, I ultimately want to claim that, despite the differences in these perspectives, the respective roles of "meaning" and "context" are in fact highly similar in these two kinds of practices. 


\section{The necessity of context-independence}

\subsection{In evaluation}

So let us consider the situation that we want to evaluate, in a rational way, the quality of an instance of linguistic communication. Such an evaluation necessarily depends on the functions that the utterances involved are supposed to perform in their specific contexts. We therefore need to have insight into such contextdependent functions of linguistic communication, for any evaluation to make sense. I wish to argue in this section that this very goal in fact also makes it necessary to develop some context-independent evaluation instruments.

Suppose we produce an analysis of the functions that some text is to perform in a specific situation, in order to derive from them certain constraints on the way the text is to be formulated, or in order to evaluate an existing text (for my purposes in this paper these two practices may actually be equated). This situation is schematized in Figure 1.

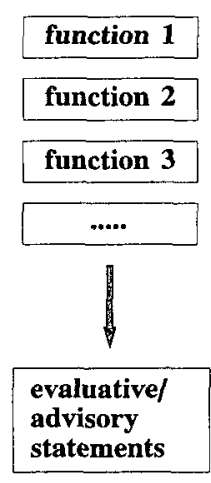

Figure 1

Is such a procedure possible? In practice, people may seem to proceed along such lines, but always a crucial assumption is involved: one must know what kinds of requirements for formulations are at all possible. In analyzing (intended) functions of a text in its context, one uses all kinds of concepts and categories to label the desired distinctions. The question is: how to choose these distinctions? Ultimately they must lead to statements on appropriate and less appropriate formulations, so they will have to be attuned to (i.a.) properties of formulations, i.e. linguistic features like words, morphemes, constructions, linear order, accent, intonation, and 
combinations of any of these Consider a purported advisory statement of the following form

\section{(1) If function $X$ is intended choose formulation $Y$}

Any such statement is vacuous if establishing a well-reasoned link between $X$ and $Y$ is not possible If one chooses $X$ in such a way that no link with a formulation can be established, 1 e with a set of linguistic features $Y$, then $X$ is useless for the purpose of evaluating (or giving advice on) formulations In other words, in such a case distinguishing $X$ is not instrumental To give a (fictitious) example one should not make a distinction between an alleged function of 'addressing one's first born son', and one of 'addressing one's other children' in case this difference never systematically relates to a set of linguistic features, at least not tor the purpose of evaluating an instance of a form of address Similarly, distinguishing between the functions 'addressing intımates' and 'addressing others' for purposes of evaluating language use, is justified only because it may be related systematically (not necessarily in a one-to-one fashion) in a particular language/culture to some set of linguistic features, such as French $t u$ vs vous Even widely accepted general distinctions such as between 'informing' and 'persuading' ultimately require such justification, which presupposes some systematic relation to linguistic features, $f f$ such distinctions are supposed to play a role in evaluating language in use

The latter proviso is important, by the way There may be other textual features for which certain functional distinctions could turn out to be more relevant than for formulations A clear example, in rhetorical terms, could be 'inventio' Texts may differ systematically in their subject matter, adequate selection of contents is an important aspect of evaluation, and there may be specific functional distinctions systematically related to it $^{3}$

Generalızing all this, we may conclude that in a perspective of evaluating linguistic usage, the selection of communicative functions - as aspects of the contexts in which a piece of discourse is to be used ${ }^{4}-$ must be constrained by the (sets of) linguistic features avallable to the users of the language, as members of a linguistic and cultural community

The argument so far is that evaluative and advisory statements on formulations can never be derived from functions only, such statements are, strictly speakıng, always based on ideas about properties of formulations too Sometimes the procedure depicted in figure 1 seemingly gives an adequate description of some process of producing evaluations, for instance when (almost) all time the analyst is spending in the process is actually allocated to determining a relevant inventory of functions But it will never actually be an adequate description of all that is required for the validation of the evaluative statements produced as output This will always also 
involve assumptions about properties of formulations, whether these are made explicitly, or left implicit. Figure 2 therefore gives a better picture of the logic of producing evaluations of usage.

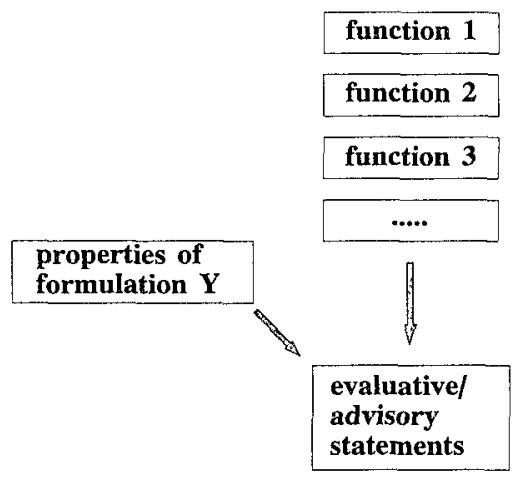

Figure 2

Let us consider a concrete case at this point, concerning the evaluation of the passive voice. Any evaluative statement about the use of the passive voice in some context presupposes assumptions about possible effects of the use of this linguistic construction. Now it is very useful to be aware of the logical structure of the situation as depicted in figure 2 , when one tries to formulate such evaluations for Dutch, because it naturally makes one wonder whether the assumptions made about the properties of passive constructions are valid; that is, being aware that one must make certain assumptions is a necessary condition for being critical towards these assumptions. As it turns out, this critical attitude is useful for Dutch, because it is important to distinguish clearly between passive sentences with the auxiliary verb worden ('to become', usually considered the form for the simple present and simple past of passives), and passive sentences with the auxiliary verb zijn ('to be', usually considered the form for the present and past perfect of passives). ${ }^{5}$ It is only the former type that systematically evokes the idea of a backgrounded agent; for that reason this type may give rise to specific problems of composition far sooner than other types of passives. Consequently, an advice on the use of 'passive' will have to be different, in the same kind of context, for English and for Dutch. ${ }^{6}$ This illustrates that evaluative statements are co-dependent on insights in the properties of linguistic formulations as such.

At this point, we may already draw one interesting conclusion for research. Since ideas about properties of relevant linguistic features are necessarily presupposed in 
evaluative statements, it is useful to contınuously make these properties the object of investigation, if only in order to avoid the pitfall of implicitly adopting naive, unwarranted assumptions that may be part of the folk view of language in our culture - or for that matter, perhaps more generally accepted but equally unwarranted and useless assumptions from any school of linguistics

In fact, this idea of continuous critical investigation allows us to take the general argument a step further The purpose of investigation is not so much producing evaluative statements of type (1) (If function $X$ is intended choose formulation $Y$ ), but rather explicating what makes such statements work, $1 \mathrm{e}$ justifying them Doing so presupposes that one knows about the properties of $Y$ making it suitable to be used in case function $X$ is intended Now this means that one necessarily abandons the context $\mathrm{C}$ where function $\mathrm{X}$ is at stake Any Justification of (1) will take the form of something like (2)

for $Y$ has the effect of so-and-so

This would be vacuous if its validity was limited to context $C$ of which function $\mathrm{Y}$ is an aspect Imagine an advice of the following kind

(3) If the persons to be informed on the use of certain company buidings during the period of reconstruction are the users of these buildings, then use sentences with second person pronoun subjects (that is, say "You may reach the parking lot via the back entrance" rather than, e $g$, "The parkıng lot may be reached via the back entrance")

Now imagine someone confronted with this advice and asking "Why?", and the answer being somethıng like

(4) Well, when you want to inform the users about the accessibility of the parking lot durmg the reconstruction period, second person address works better than, for example, a passive construction

This person now would have every reason to protest Such an answer is just not a justification, but at best a reformulation of the advice The answer to the question "Why?" becomes a justification only if it minımally includes a generalization over context $\mathrm{C}$ and other contexts, for example

(5) Well, this particular context $\mathrm{C}$ where function $\mathrm{Y}$ is at stake, looks like other cases in a number of respects $(\mathrm{a}, \mathrm{b}, \mathrm{c}, \mathrm{)}$ ), and it is in that kind of contexts that second person address generally works better than other types of formulation

This will still not be an explanation, which would at least require filling in the variables in the formulation Precisely because of its schematic nature, however, it does show nicely that generalization is a general property of justification 
All in all, we have now reached the following position: not only are insights into properties of any formulation $\mathrm{Y}$ required for evaluation, these properties also have to be stated independently from the function $\mathrm{X}$ to which $\mathrm{Y}$ may be related in a specific context $C$; such a statement thus necessarily involves constancy over contexts.

\subsection{In interpreting language}

Evaluation and advice, as meta-linguistic activities, may seem to be rather different from ordinary language use, but this difference in levels actually does not have many consequences, I believe, for the view of the relation between language and context. That is to say, recognizing the necessity of generalizing over contexts is little more than recognizing a fundamental feature of language use itself. If we recognize a particular event as the production of a linguistic element, say of the word 'donkey', we thereby acknowledge certain similarities between the present situation of use and previous experiences in which this element was used; i.e. something justifying the use of 'donkey' now, is that some aspect of the present situation looks sufficiently like other situations where 'donkey' was justifiably used. ${ }^{7}$ If we could not make that kind of connection, we simply would not be recognizing whatever was being said or written, as an instance of the word 'donkey'.

Notice that this in fact formulates a minimal condition of intelligibility: to understand something must involve acknowledging some similarities between the present usage event and previous ones. To the extent that we do not succeed in making this kind of link for (part of) an utterance, we have not understood it - for this is just what 'understanding' means. So it seems that processes of evaluation or advice and those of understanding have an important common characteristic: they presuppose some kind of generalization over contexts, and thus independence of a particular context, as a feature of linguistic elements. Similarities between distinct usage situations (the present one, and previous ones) function crucially in both evaluation and understanding of language.

Now this seems to conflict with the everyday experience we started out with: our inability to explain the meaning of a word without reference to some context (cf. the Lyons-quotation). It is therefore useful to elaborate a bit more on this point before returning to the main line of the argument.

One major area where linguistic meaning does not, at first sight, seem to be context-independent, is that of metaphor. Still, it is precisely generalization over different contexts that underlies its pervasiveness. Unlike what the layman ${ }^{8}$ may think, a metaphor is not the use of a linguistic expression in another than its 'literal' meaning; even though there may be some cases where this description might make 
sense, it cannot be definitional. This has been known for a long time, but for the present argument it is highly relevant to elucidate the point once more

In Acket \& Stutterheim (1960), a high school textbook on stylistics unfortunately out of print since then, Stutterheim relates the story of a man receiving a parking ticket, who, in his frustration, calls the officer a donkey As a result, the man has to face charges, and is sentenced to pay a fine for insulting an officer on duty. He tells the judge he regrets his behavior, but he also asks for a clarification.

Man 'Your honor, if I understood correctly, I'm not allowed to ever say "donkey" to an officer?"

Judge 'That's what I've tried to make clear, man'

Man 'But I suppose I may say "officer" to a donkey'

Judge 'I see no legal objections to that, of course"

Man (mumbling, but loud enough for everybody to hear) ' $\mathrm{Hm}$, so I am allowed to say "officer" to a donkey"

He then walked over to the upholder of justice, and said, with a lot of friendly emphasis 'Goodbye, officer' - causing Homeric laughter in which the addressee was the only one not to participate

(Based on Acket \& Stutterhem 1960.81)

As Stutterheim points out, this demonstrates that in calling the officer "donkey", the man had not said one thing ("donkey") and meant another ("stupid person"); on the contrary, for him the officer really was a donkey. In modern terms, he simply "categorized" the referent as a donkey. That not all features that may possibly justify the use of that word in other contexts were actually present in this one, does not in itself make the use of that word more special than another one.

In another way, Lakoff \& Johnson (1980:5) make the same point when they say that in many cases other ('literal') ways to talk about certain topics do not even exist, so that all one can say is that, for example, the metaphorical way of talking about arguments (like 'winning' or 'losing' them) is also the literal way. Similarly, Rumelhart (1979) and Bolinger (1980, ch.12) have pointed out that the processes of producing and understanding metaphors are indistinguishable from the processes of language use per se: we continuously compare new experiences to old ones be it in order to arrive at the most appropriate way of labelling them (in the case of production), or at the most appropriate interpretation (upon encountering a word used and having to interpret it, i.e. aligning it with previous instances). The point of metaphor is not a point of language used in some special, deviant way, but of conceptual mapping: knowledge of one domain is used to (partially) structure another conceptual domain, creating certain inferences and blocking other ones. 
The conclusion must be that metaphors, like other instances of language in use, are interpreted in the way they are, precisely because they are taken to embody generalizations over contexts.

\section{The necessity of context-sensitivity}

\subsection{In evaluation}

Returning to the main line now, we may state that if we want to evaluate an instance of an expression on some particular occasion, we should have some idea of its meaning, independently of that specific context. But this does not mean that the construction of such an idea is completely unconstrained by considerations of context, including considerations concerning the actors' specific purposes in the communicative situation. This may seem another paradox, so let us quickly try to resolve it. The idea is simply that some kinds of meaning formulations are more suitable for purposes of evaluation than others. For example, truth-conditional semantics in itself does not have an easily discernible relationship with communicative purposes, i.e. the things that are important measures of adequacy of expression. The reason is not that truth-conditional semantics is, in some absolute sense, wrong, but rather that 'truth', the central concept of correspondence to (a model of) reality, never exhausts the relevance of an utterance. At any time, the number of propositions true for a situation is infinite, so being true can never justify the selection of any one proposition in particular. One could, of course, conclude that this only goes to show that pragmatics is really independent of semantics (and vice versa), but I consider it too basic a point that language is used by people for communication, to think that this would have no effect on its structural properties; I will not try to argue that position here, but simply assume it. ${ }^{9}$ Consequently, statements about the conditions for the truth of an utterance will at best have a distant connection with statements about its adequacy and relevance as an instrument of communication. So for evaluation purposes not all approaches to meaning are equally useful; taking meaning to consist in, essentially, correspondence to the world may provide some criterion for evaluation (say in applying Grice's first Maxim of Quality) but is at best very limited. ${ }^{10}$

Something similar holds for certain kinds of psycho-linguistics, in my view. I have in mind approaches that attribute some context-independent degree of complexity to expressions, measured, for example, as the number of words per sentence, etcetera. The idea is that expressions with a high score are more difficult to parse than other ones with lower scores, so that some expressions only allow for (easy) processing by people with high education, whereas more simple expressions could 
be (easily) parsed by everybody (for a recent critical survey, see Jansen 1995). Note that such an approach in principle allows for some evaluative statements. An example could be the idea that a passive construction is complex, and therefore harder to process than the corresponding sentence in the active voice. This is the type of applied or normative linguistics which Maureau (1983) describes as its initial stage, but which is certainly not dead (as an example, see Petrič 1992). Its general character can be depicted in figure 3 .

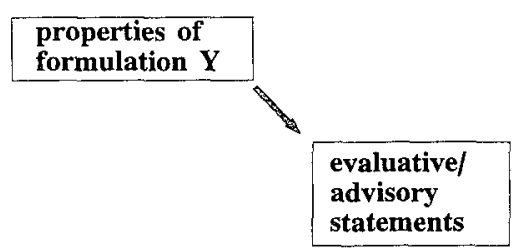

Figure 3

Recall that we set up figure 2 in response to the idea that consideration of contextual functions could lead to evaluative statements independently of a semantic analysis of the linguistic elements involved. Approaches of the type depicted in figure 3 are in a sense complementary: they embody the idea that consideration of language independently of context can lead to evaluation.

I want to claim that this type of approach is equally wrong, though for different reasons. The problem discussed in section 2.1 concerned the logic of the argumentation: I tried to show that evaluation necessarily presupposes ideas about meanings generalizing over contexts. Here the problem seems to be a misunderstanding of the nature of linguistic communication. The point is that it seems silly for a language to have both complex and simple ways of doing things if the former do not have an advantage in certain contexts - at least one feature that, if one wanted to communicate it and one did not have linguistic resources to do the job, would require a whole lot of energy and trouble to get across. The alleged complex formulation therefore is, in that context, actually the simplest thing to do, especially if it is reasonable to expect the addressee to know the expression in question. In short, in view of the communicative function of language, the whole notion of some expressions being inherently more complex than others is suspect. "Abstractly, the idea is that an utterance is never really processed (and 
thus should never be evaluated) in vacuo, but always with respect to some context. Even in terms of processing efforts, the point is that the adequacy of using a particular linguistic construction should be evaluated in terms of the net sum so to speak, of the effort of processing the linguistic and the contextual information together. I will come back to this issue in section 4 .

For now, the consequence of this view amounts to a requirement on the formulation of meanings, which are, as I said, themselves context-independent. The requirement is, simply, that these formulations should allow for a useful combination with descriptions of communicative contexts, in order to contribute to an evaluation of linguistic communication. Just as the formulation of functions must be constrained by the set of linguistic expressions available in a language, the formulation of meanings must be constrained by the demand that they be sensitive to context features, in order to allow for evaluation in an indefinitely varying set of contexts.

So meanings are not only generalizations over contexts (section 2); in order to be really useful in evaluative or advisory practices, they also have to be formulated in such a way that they allow for adaptation to context. I will now try to illustrate both points by means of an example mentioned before: the passive construction (in Dutch).

Cornelis (1997) makes an interesting point concerning the use of passive constructions in two newspaper articles on Ajax winning the national league in Holland in 1994. One article is from Het Parool, an Amsterdam newspaper, another is from NRC-Handelsblad, a national paper (office in Rotterdam). In some respects, passives are used similarly in both articles; typically, individual human agents take precedence as subjects, especially in active sentences. However, in one area there is a significant difference. Whereas Ajax as an agent has about the same frequency in both articles, it never is an agent in a passive in Het Parool, while it does occur in this role in NRC. As Cornelis points out, this is quite understandable given the distinct attitudes of the newspapers with respect to Ajax: Het Parool naturally identifies much more with Ajax than $N R C$. Furthermore, this difference corresponds with other characteristics of the texts (headlines as well as contents): $N R C$ has a much more cynical view on the way Ajax became champion than Het Parool has.

In such a line of thought, the relevant property of the passive construction is that it is an operation on the relation between the producer of the utterance on the one hand and the agent in the event being described on the other: as a reader one understands that the writer does not see the agent quite like s/he would see her/ himself in such an event (see Cornelis 1995, 1997, for theoretical elaboration). This formulation of the meaning of the passive makes it possible to have the concrete effect of the use of the construction being co-dependent on the context. In fact, it even makes it impossible to produce an evaluation of its use independently of a 
specific context of use the possibility of evaluation only arises if we know at least who are communicating and about what For example, if Het Parool would have had Ajax in the role of a passive agent, we could have felt justified in advising the author to change these sentences, but in the $N R C$ context, that advice would be out of order

At the same time, it should be noted that the formulation of the function of the passive itself generalizes over such contexts Characteristics of the context, though always co-determinants of the effects of the use of language, do not enter into this formulation Formulating the function of the passive precisely means stating a way, or a number of related ways, to connect the different contexts in which its use may be considered justified

As an aside, note that for a language user to be able to draw practical consequences from an analysis, it may sometimes be sufficient to formulate the function of the passive context-independently, for example as "It decreases the degree by which the producer of the utterance identifies with the agent", leaving the application in particular cases to the user An evaluator or adviser sometimes does not have to spell out types of contexts or consequences explicitly, in order to enable users to use a semantic/pragmatic analysis In a sense, this is fortunate in view of the fact that the number of possible contexts is, of course, infinite It is often useful for purposes of instruction to lay out a number of different types of contexts, and to explore the details of the effects of a linguistic expression in those contexts, but this can never lead to a procedure for evaluation Nor is such a procedure necessary, as members of the culture, users may agree on relevant context features without a procedure for fixing them As generalizations over contexts, meanings are a kind of schematized rules for using words and constructions, and are as such often sufficient for application in specific situations

Complementary, there may also be situations where it is not necessary to spell out the meaning of the passive, but rather some features of the context, the function that communication is to fulfil and the like, in order to reach agreement on the appropriateness of the construction In any case, such practical differences should not obscure that when we, as analysts, try to understand what constitutes this approprateness, both features of language and features of context are necessarily taken into account, and are in fact integrated

\subsection{In interpretıng language}

In discussing the necessity of context-1ndependence I claimed that the process of evaluation is, in this respect, actually similar to that of interpretation Recognizing some activity as an instance of language use involves recognizing similarities 
between the present context and other ones as much as evaluation does. So the question now arises whether the same parallel holds for context-sensitivity. Do processes of language production and interpretation themselves involve adjustment to context too? In other words: are context-sensitive formulatio's of meanings useful for descriptive purposes as well? Not surprisingly, I think the answer should definitely be positive. Let me try to make the point by means of ciscussing some relevant cases, the use of passive constructions once again, and finally metaphors.

The usefulness of a context-sensitive view of the function of the passive is clearly demonstrated by some observations on the distribution of passives. A telling example is that of the Queen's speeches at the openings of the Dutch parliamentary year over the last decade (Van der Veer 1994). A non-context-sensitive account, for example one that considers the passive a feature of formal style, would seem to predict that passives are randomly distributed over the text; after all, it is formal from beginning to end. Actually, the distribution turns out to be heavily skewed. When one distinguishes, on independent grounds of content, between clauses announcing policy measures and clauses describing events in reality (naturally as the government sees them), passives are really far more frequent in the former than in the latter. From the functional point of view formulated before, this comes as no surprise: most, if not all policy measures are going to have a negative effect on at least part of the population, so it is only natural that there is a tendency not to present the agent in these text segments as an entity to identify with. A look at some details confirms the idea that the government actually has no general problem: depicting itself as fully responsible for its actions (i.e. in subject position in transitive clauses): it happens regularly in parts where the government clearly expects its actions to be applauded rather than denounced. The observed correlation with formality thus receives a functional explanation: announcing policy measures is done in a formal type of discourse, but the former is the real explanatory factor.

The necessity of assuming context-sensitivity of meanings can also be demcnstrated in the domain of metaphor, i.e. the same area of phenomena that I used in section 3.2 to illustrate the context-independent constancy of meaning; there I argued that metaphors precisely illustrate that point because the mapping from one domain to another has to preserve conceived structure from the 'source domain' in order for the metaphor to structure the contents of the 'target domain'. But the actual selection of what is preserved and what may be discarded in a metaphorical mapping, is not constrained (beyond convention), and thus highly sensitive to context. $^{12}$ Let me illustrate this point with one of the most pervasive metaphors in different types of (non-literary) texts: personification.

One common metaphor in Western culture is A STATE IS A PERSON (Chilton \& Lakoff 1989; Lakoff 1991; for Dutch: Lammerts \& Verhagen 1994). The metaphor 
has a number of entailments with important consequences for foreign policy (the most general one perhaps being the assumption that a state is a behavioral and intentional unity, its actions being the result of its intentions, and not of, say, internal conflicts). One such entailment is that states may be in different life-stages: some are children, in need of guidance, education, and correction, while others may be considered mature, and thus natural candidates for leadership in the community of state/persons. The 'usefulness' of this piece of mapping from a source to a target domain lies, of course, in the understanding, and sometimes the justification, that it provides for a number of international relations, for instance those between developing and developed countries.

Now not all aspects of the life-stage-entailment are necessarily mapped onto the target domain; while there are no structural reasons for their absence, old-age and death are not 'activated', at least not in Western countries, as features of the personification of states when, for example, the relationship between Western and Third-World countries is the target domain. The reason that this does not happen seems evident: it is these Western countries that would be implied to be closer to old-age and death, with all obviously undesirable consequences for their claims to power and leadership. ${ }^{13}$

That the absence of this mapping is not due to a structural constraint is manifest from a situation where a structurally similar (but non-conventional) metaphor does involve this mapping. The former Dutch Minister Mr. Winsemius, once described government policies as having a life like a person (de Jong 1995): they start out as the children of their initial designers (usually government officials), then mature and become independent from these initial designers, and finally, when the goals have been reached, they have to die. Here the whole point of the personification, the way the metaphor structures the target domain, makes no sense if it would not include the final stage of life.

In fact, the notion of a life cycle itself does not have to take part in personification at all. Computer manuals, for example, sometimes personify the machine or the program (with expressions of the type Program $X$ thus frees you from having to perform task $Y$, or: The computer then asks whether you want to continue), but in those contexts the idea of a life-like development makes no sense (in others, of course, it may be more suitable).

So what we see is that knowledge of the source (of the concepts "person" and "life") is preserved in metaphorical use, but there is no way of saying, in advance of the metaphor, which aspects of this knowledge will actually get mapped and which not. Important for the purpose of my present argument is that the meaning of 'source-domain-elements' must be sufficiently structured to allow for the activation (or, as Reichling (1967:325) called it: "actuation") of different features on different occasions. 
To return to the main line once again: both in evaluating and in describing language use, it seems inevitable to conceive of meanings in such a way that they have no particular way of application built into them, but rather have something like 'open places' to be filled in by information from other sources, or constitute some structured complex from which aspects may be discarded depending on such 'other information'. First, it turns out that context-sensitivity is a feature of evaluation and description alike, just like context-independence (cf. section 2). Second, it should be noted that this way of conceiving of meanings makes it impossible to think of them as 'building blocks' of interpretation. This metaphor must be abandoned in favor of the idea that meanings are instruments for interpretation, or more technically: the context-independent meanings of linguistic units are constraints on interpretations. A meaning is not a part of an interpretation, but rather specifies a (set of) condition(s) that an optimal interpretation should meet.

This view of meaning also opens a possibility for reconsidering the relation between meaning and context. From the point of view of a cognitive system, a feature of the context is just another constraint on interpretation. In that sense, context is not altogether different from linguistic meaning. Now this entails a certain view on the nature of a cognitive system as (at least to an important extent) a constraint satisfaction system, and it therefore seems appropriate to explore some important aspects of such a view. This is what I will turn to now. I will try to argue that such a view has both a certain plausibility and some interesting consequences precisely for the relation between meaning and context.

\section{Parallel processing and the equivalence of linguistic and non-linguistic context}

Recall the analysis of the passive construction mentioned in section 3.2. It was claimed that the use of this construction entailed that the speaker/writer does not view the agent quite like him/herself. It is easy to see that on this view, the way a passive construction is processed is always coordinated with processing (other) features of the environment. Consequently, there never is a moment in the process such that what someone understands could be specified in no other terms than the general, constant function of the passive. Rather, this view suggests processing of all kinds of information (linguistic and otherwise) in parallel, constraining the construction of an interpretation. The idea of parallel processing has recently been developed in a computational approach to modelling cognition called "connectionism", or "parallel distributed processing" (PDP), and I would like to use some central concepts from this approach as a model for the analysis of languageas-it-is-actually-used that takes its complexity into account without becoming too complex itself. ${ }^{14}$ 
Connectionist models have been developed, at least partly, in response to standard models that use the serial digital computer as a metaphor for human cognition Undoubtedly, human cognitive behavior is very complex, and the standard way of modelling it has been to assume different modules of computation, each performing a specific operation on its input in order to produce an output which is then further processed by another module The complex overall task is thus split up into a number of relatively simple parts This approach has been successful in a number of respects, but is not without problems, especially as far as realistic modelling of processing is concerned For certain analytical purposes, there need be no doubt about the usefulness of distinctions between information based on, for example, linguistic evidence on the one hand, and non-lingustic evidence on the other, but projecting such analytical distinctions as input-output modules onto the human mind is not justified on the basis of such usefulness only, and also probably wrong in view of elementary limitations (esp speed) of single processing units in individual brains ${ }^{15}$

The connectionist approach, in contrast, assumes parallel processing of inputs by massive numbers of simple units that spread activation through a network as they are interconnected (with different and variable degrees of strengths, or "weights", and with inhibiting as well as excitatory connections) The output produced by such a system is not represented in any way within the system (no internal symbols), but is determined by the entire (distributed) pattern of activation of the units connected to the output unit Langacker summarizes the properties of the resulting systems in the following way

First, [ ] PDP models have important analog properties, in that both connection weights and levels of activation can vary over a contınuous range of values Second, there is no central processing unit, and no program telling the system what to do Each unit autonomously performs a strictly local computation it sums its inputs to determine its own level of activation, and hence the degree of activation it passes on to other units (depending on connection weights and whether the connections are excitatory or unhibitory) Third, a computation does not proceed serially, one operation at a tıme, but instead shows massive parallelism, as all units simultaneously perform their local computations in mutually interactive fashion Fourth, the system's memory resides in connection weights, which are the only things modified by training Memory is therefore distributed rather than local, since an item of memory is not inherent in any single weight, but in a configuration of weights that collectively give rise to a particular computational result [ ] Finally, no distinction is drawn between rules and representations, for there are no explicit rules at all-the system merely learns to respond in certain ways to particular kinds of input Rather than being distinct and independent entities, the generalizations it extracts are implicit in the similarity of its responses to sımılar input patterns (Langacker 1991 527) 
Connectionist models are particularly suited to model situations involving so-called soft constraints: a 'rule' that makes a particular interpretation more likely, given a certain kind of evidence, but that may be violated, or better: that simply will have no effect, when enough other such rules (each of them in itself equally 'soft') suggest another interpretation. For example, given a distribution of connection weights that represents the constraints among interpretations for each of the corners of a Necker cube, a connectionist net will easily settle for one of the two coherent interpretations of such a cube, even if some of its input units provide contradictory evidence. Note that an activated input unit (detecting the presence of some perceptual feature) only provides one of the constraints, which has no qualitatively different status as compared to other constraints.

It is this conception of constraint satisfaction, as a way a cognitive system operates with evidence from its environment, that I think is particularly useful for a further clarification of notions of meaning and context, and their interrelatedness. Interpretation of a linguistic usage event is in actual practice interpretation of the entire event, and not just the linguistic forms used. We take the words and constructions used, ànd other perceived aspects of the situation, as soft constraints on the representation we are to build of the entire situation. In other words, we try to reach a new cognitive state which is optimal in the sense that the degree of satisfaction of the totality of constraints is maximal. This may entail that some constraints, although present, do not contribute to the new cognitive state at all: if the actual maximum of constraint satisfaction is such that some constraints do not contribute to it, or perhaps even have a negative contribution, the corresponding cognitive state will still become the new one - without the system having to decide to 'cancel' the contribution of these constraints. Take the simplified picture in figure 4 as an illustration.

Left a number of units is listed, including the degree to which they constrain some interpretation $A$; activation of a unit provides either a positive indication for interpretation $A$, or a negative one, as indicated by the plus- and minus-signs; the strengths of the connections are indicated by the numbers, representing the amount with which the activation of the unit is to be multiplied upon being passed on, as well as a sign indicating excitation $(+)$ or inhibition $(-) .{ }^{16}$ For the sake of presentation, the threshold value for $A$ is assumed to be 1.5 (if the activation level of this unit is lower than 1.5, it does not 'turn on'; if the level reaches 1.5 or higher, it does turn on). Each unit passes some activation (determined by the weighted sum of the activations passed on to it from, ultimately, 'perception units', via connections of different strengths) on to the output. Suppose that the activation put out by each of the units 1 and 2 is 1 , while that of 3 is 0.2 , and no other units connected to $A$ are activated. The total activation passed on to $A$ then is 
constraints:

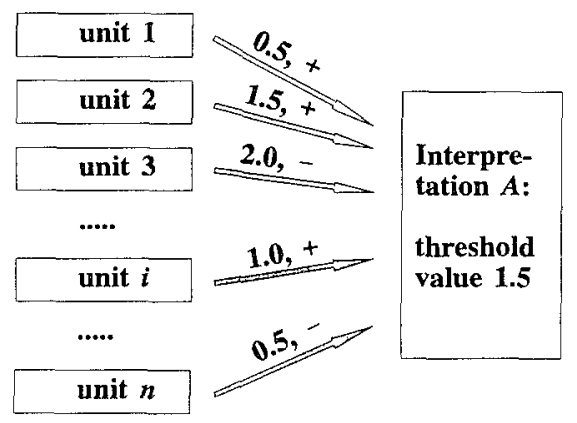

Figure 4

$\left(0.5^{*} 1\right)+\left(1.5^{*} 1\right)-(2.0 * 0.2)=0.5+1.5-0.4=1.6$ which exceeds the threshold value, and so $A$ will turn on: the system displays interpretation $A$ and seems to favor constraints 1 and 2, while discarding constraint 3 even though there is evidence for it in the input - but without any 'operation' that specifically cancels the effect of constraint 3.

Now consider the same configuration, but with unit $n$ passing on an activation of 1 . Then the total activation into $A$ is $0.5+1.5-0.4-0.5=1.1$, which is below the threshold value of 1.5 , so that $A$ will not turn on; now the system seems to discard constraints 1 and 2 even though there is evidence for them - again without any operation on those constraints. I leave it to the reader to see for himself how some juggling with different levels of activation can produce many different patterns leading to an interpretation either turning on or not, and that all patterns leading to the same end-state need not have a particular activated unit in common (i.e., an interpretation need not have 'essential' features).

It should be emphasized that this is a gross simplification of what is going on in connectionist networks; ${ }^{17}$ it nevertheless suffices to serve as a useful model for clarifying some of the complicated issues in the analysis of actual language usage. That is to say, I will explore the consequences of the idea that the meanings of linguistic elements may indeed be viewed as constraints on interpretations, i.e. as activation (triggered by the perception of a linguistic element in the input) being passed on, in an inhibitory or excitatory way, to one or more possible interpretations. I will highlight three aspects that seem to me to be of particular interest for our conception of meaning and context. 


\subsection{Identity of constraints}

The first implication of this approach that I would like to bring to the fore is that the character of the constraints themselves does not change under different interpretations - not even if their contribution to an interpretation is negative. A concrete example illustrating this is the following: the meaning of "red" as a traffic light (the constraint connecting unit 1 to a decision on how to proceed) does not change when in a specific case I decide to drive on because the sum of all available input (constraints $2-n$ ) has led me to the conclusion that the operating system is malfunctioning; the red sign does not loose its meaning as a constraint against driving on, not even in this specific case. ${ }^{18}$ This sheds a new light on the status of one type of statement that gave rise to this discussion (see section 1): "X means something different in context A than in context B". Such a formulation suggests that the nature of $\mathrm{X}$ does change because of the context. We may now hypothesize that this kind of statement may have been inevitable, and therefore still appears somewhat natural, because our conception of meanings entering interpretations (the former somehow being part of the latter) simply made it necessary. I.e., it may have been the result of the naive idea that the meanings of elements are actually the building blocks of interpretations, things being passed on by a 'sender' through some 'channel' to a 'receiver' who supposedly constructs an interpretation by assembling them - i.e. the powerful but erroneous metaphor for linguistic communication that has been baptized the "conduit-metaphor" by Reddy (1979; see also Langacker 1987:452ff., 1991:508).

A very illuminating example, both for the usefulness of the constraint satisfaction model and for the sloppiness of naive use of the term "meaning", is provided by Hutchins (1995). Hutchins considers navigation on navy vessels. This involves regularly "taking the bearings" of three landmarks (determining their direction with respect to the ship) in order to determine ("fix") the position of the vessel. Ideally, the three bearings should be taken simultaneously, but when less than three persons are on this job, this is of course impossible. The optimal order (introducing the minimal amount of error) is then to first take the bearing(s) of the landmark(s) that is (are) to the side of the ship (so-called beam-bearings): those are the ones whose angular speed with respect to the ship is changing fastest, while the orientation of a landmark that is more or less ahead will hardly change in the time necessary to take the first (two) bearings. Taken in that order, the actual bearings will most closely resemble the 'ideal' situation of being taken simultaneously. This procedure is summarized in the "rule of thumb": "Take the beam bearing first" (Hutchins 1995:206).

As Hutchins points out, the application of this rule is straightforward with one person on the job, but not so in a situation with two observers (and this is the usual situation: one observer on port side and the other on starboard side). Taking the 
three bearings then becomes distributed (one observer taking one bearing, the other one taking two). This introduces indeterminacy as to the identity of "the beam bearing":

When the rule is invoked [ ] by a single quartermaster standing watch alone, the beam bearing refers to the bearing in the set of three that is nearest the beam of the ship, and the sequence specifier "first" is established with respect to the entire set of three bearings (Hutchıns 1995 217)

That is, the constraints present in the situation include the linguistic elements beam and first, and also knowledge of the set of three bearings to choose from.

In the group version of the task, a pelorus operator [observer on the wing of a ship - AV] cannot always determine whether any bearing he has been assigned is nearer the beam than any bearing assigned to the other pelorus operator [ ] It is as though other words were missing from the simple statement of the rule A more explicit version of the rule in the solo watchstanding case would be "Of the set of three bearings, shoot the beam bearing first" It is not necessary to say these words in the solo watchstanding context, because the entire set of three bearings is the watchstander's responsibility Their presence in that context is not needed [ ] (ld )

In the group version, each of the observers lacks some evidence (input) that, in conjunction with the rule of thumb, provided the solo watchstander with sufficient constraints to establish a unique interpretation. In the absence of such input, the same rule turns out not to provide a sufficient constraint (on its own) to determine such an interpretation. ${ }^{19}$ So here we have a nice example how a number of different (positive) constraints turn out to determine a particular kind of interpretation. As long as the second type of situation has not occurred, the relevance of the 'contextual' constraints might escape our attention, so that we might be under the illusion that the interpretation is entirely determined by nothing else than the meanings of the expressions involved.

Interestingly, it seems as if Hutchins himself is somehow still caught in this belief, because the sentence I left out of the middle of the last quotation reads as follows:

A pelorus operator stationed on one wing of the ship cannot give either of these words the meaning it has for the solo watchstander. (ld.)

And on the next page it says:

The pelorus operators need a meaning of 'beamiest' that they can apply on the basis of what they can see, and they cannot see all three bearings at once Transporting knowledge from 
the solo performance context is very problematic. It may require changes in the meanings of words.

In my view, the entire description as Hutchins presents it rather invites the conclusion that "first" just means what it means, and that this is precisely the reason why it does not suffice in a situation that does not provide the interpreter access to the entire relevant set. But his own formulation creates the impression as if the context enables the solo watchstander to give some specific meaning to the words, rather than to interpret the entire situation coherently and in a unique way. Similarly, I would not say that the change in the task situation requires changes in the meanings, but rather, as his own formulation suggests, the addition of some more linguistic input, in the absence of certain specific non-linguistic constraints. Note also that it is at best misleading to suggest that the non-linguistic contexts "disambiguates" the meanings of the words, or anything of that kind. This would seem to imply a two-stage process (having the linguistic information changed, before it is applied to the world), whereas a one-stage process (parallel application of constraints to form an interpretation of the world) is simply sufficient. But it looks as if the folk model of conceptualizing communication as 'unpacking what is in the words' is so pervasive that it is hard to formulate a description that avoids invoking this model. We have the illusion, on the basis of some standard set of situations, that what is communicated is only in the words, and when we then encounter a situation in which the same words are used, but something else (or nothing) is communicated, we sometimes still do not see through the illusion, and then describe this situation as if the words have a different meaning due to the different context.

But we have already seen that upon elaboration this view is untenable: meanings must be conceived of as somehow constant, generalizing over contexts (section 2). We can now also see how a view of meanings as constraints on interpretations (rather than as parts of them) allows for a more consistent picture. If interpretations arise from patterns of distributed information, the relation of a linguistic element to an interpretation may be very different on various occasions, but without the element as such changing its character from one occasion to another: it just provides positive or negative activation for the interpretations it is connected to, and it does so constantly. But since the total activation of an interpretation is always determined by several inputs, with different weights and directionalities, there is no unique way in which the constraint will show up in all its uses. For example, there is no way of knowing in advance of an interpretation (so without having considered the entire pattern of activation) whether a constraint is going to support or contradict it, as the discussion of even the simple case of figure 4 has demonstrated. But in all conceivable cases, it remains true that when 
certain conditions in the environment hold, a constraint leads to passing on some specific degree of activation.

Note that it is indeed not only meanings that can be usefully conceived of as constraints on interpretation. Features of the context function in the same way. In the preceding paragraphs, we appear to have encountered different 'kinds' of context: position in an utterance, domains in the case of metaphorical mappings, wider cultural knowledge, the identity of the communicative participants, etcetera. What these aspects have in common is that they all fuiction as constraints on the interpretation of the relevant usage events; in that sense, context is the set of relevant non-linguistic constraints on the interpretation of linguistic usage events. But note that from the point of view of constraint satisfaction as such, these constraints do not necessarily differ in nature: they are just constraints on interpretations. Put differently: a piece of information about a usage event, constraining its interpretation, may be obtained from linguistic input in one case, and from non-linguistic input in another - that does not necessarily lead to different interpretations. In the next section, I will explore the consequences of this idea.

\subsection{Language as context}

Consider figure 4 once again. In the discussion so far I interpreted some constraints as being of a linguistic nature, and others as non-linguistic (contextual). However, nothing in the constraint satisfaction model as such imposes such an interpretation. For a processing system, it may actually make no difference, when unit 1 represents a linguistic element perceived in the situation, whether unit 2 represents a nonlinguistic feature, or a linguistic one. With respect to the linguistic constraint represented in unit 1 , unit 2 just provides 'context'.

The first thing to note is that this makes us aware on the relational nature of the notion of "context". Notice that we are actually taking a meta-linguistic point of view when we call something "context". We usually ask for the contexts of words or expressions (compare the quote from Lyons at the beginning), but not for the words or expressions in some context, or, for that matter, for the linguistic context of certain visual stimuli. But for a system that is just processing constraints associated with features perceived in the environment ("information"), this difference does not exist as such; rather, there are just these different features of the environment (some of which may be linguistic) on the basis of which an interpretation is constructed. At a certain point, we focus on one particular piece of information that is presently considered to be worth specific attention; once it has been focused on, the rest becomes its context, but not sooner. 
So the notion of "context" is a meta-notion, not necessarily corresponding to a distinction relevant in the same way at the object-level. Again, for an interpreter in the world, there is no reason to systematically give primacy to some types of information over others; all there is are constraints on interpretation, some strengthening each other's effects, and others competing. Sometimes linguistic information ("the text") will be used to help fill in some details of a representation, the main lines of which have already been established on the basis of other data, sometimes the situation will be the other way round; it is clear that there will be no sharp boundary between these two ways of balancing linguistic and nonlinguistic information. All in all, this is another instance where we have to take care not to project our way of conceptualizing things in an analysis, useful or even necessary as it may be, onto the situation analyzed.

The second consequence is that the information providing the context for some piece of linguistic information may very well be linguistic itself without it making any essential difference. In other words, there is no reason whatsoever to make a categorial distinction between interpreting utterance $\mathrm{A}$ in a situation in which features $X$ and $Y$ are perceived, and interpreting $A$ in a text somehow evoking $X$ and $Y$. Again, in the picture of figure 4, there is just a set of constraints. The cognitive task of constraint satisfaction does not alter essentially if some of the constraints are non-linguistic and others linguistic, or if all constraints are linguistic. Thus there seems to be no basis for attempts that try to distinguish autonomous from non-autonomous linguistics in terms of the former 'taking extra-linguistic factors into account', simply because it is not clear, from the point of view of a parallel processing system, that 'non-linguistic information' and 'other linguistic information' differ systematically in their causal cognitive properties. ${ }^{20}$

The reason why I emphasize the last point is that it shows why, in an interpretive practice, all material on which interpretation is based may legitimately consist of text. Interpreting a piece of discourse with respect to other non-linguistic constraints is not essentially different from interpreting it with respect to other linguistic ones. And why should it? After all, what all pieces of information have in common is that they only give rise to constraints within a cognitive system. Why should there be any deep difference between, on the one hand, Hutchins's solo watchstander from the previous section, constructing an interpretation on the basis of the linguistic information "Take the beam bearing first" and the non-linguistic knowledge that there are exactly three bearings to take, and on the other hand someone constructing an interpretation on the basis of two pieces of linguistic information, viz. "Take the beam bearing first" and "There are exactly three bearings to take"? We know from psycholinguistic research that the precise linguistic form of an expression is lost very quickly (it hardly 'survives working memory'), and that only a far more abstract conceptual representation is preserved. 
The consequence of this fact should not be that we as analysts no longer have to pay attention to the details of utterances (they are still causally related to the conceptual representation!), but that for purposes of interpretation we should not make a deep distinction between linguistic and non-linguistic context.

I conclude that we both may and should stop reasoning as if "context may affect meaning", or even "context may affect interpretation". The danger of such statements is that they are simple transitive clauses, evoking a model of one entity directly exerting some force on another, which is thereby changed (cf. Kemmer \& Verhagen (1994), and the references cited there, especially the folk model of causation in Lakoff (1987); also Bolinger (1980:157)). In other words: such statements easily suggest that the relation between context and meaning or interpretation may be direct, whereas they are actually never linked anywhere but within a 'cognizer', processing several pieces of information (some of which are in his/her own long term memory) in parallel in order to arrive at a coherent interpretation that will guide him/her in taking the next step (usually small, sometimes big) in life. When we use "context", "meaning" and "interpretation" as subject and object in simple clauses, we might just forget that it is people who use information from all kinds of sources to construct representations of the communicative situation. Even worse, it contains the risk of seeing things that do not exist, magical immediate connections between features of the context and features of language. In actual fact, both have to be recognized by a human being in a situation. The connectionist approach to cognition provides us with a conceptual model that allows us to see how a cognitive system may take a number of different constraints as input to form one coherent interpretation, and how it can use the same constraint to contribute to different interpretations in a consistent and straightforward way.

\subsection{Evaluation, interpretation and semantic analysis}

Finally, I would like to turn to the question of the status of evaluative and advisory practices of linguistics advocated at the end of section 1, that functioned as frame of reference for the rest of the discussion.

In terms of the constraint satisfaction approach, the evaluation of language use can be seen as a judgment on three aspects. The first is the issue whether a constraint invoked by some linguistic feature is consistent with the overall interpretation, i.e. whether it contributes positively to the optimum of constraint satisfaction, or negatively (only the former being a basis for positive evaluation). The second aspect is that of the relative weight of its contribution, i.e. the portion of a particular feature in the total level of activation (the higher this portion, the 
'more important' the feature involved is for the interpretation, and the less easily it can be left out or replaced). The third aspect is the level of activation itself, interpreted as strength of an interpretation: if the linguistic input does not suffice to strongly support one particular interpretation, this fact may be a basis for negative evaluation. ${ }^{21}$

Of these three aspects, I will only discuss consistency and level of activation in greater detail. As far as I can see, weight will be especially important in evaluating literary language, perhaps even specifically poetry, where changing one word may make an immense difference. But most ordinary communication seems to be characterized by a situation of several elements 'working in parallel' to establish an interpretation.

To start with level of activation - the strength or weakness of an interpretation I think it may in many cases actually be reduced to the other two aspects, especially consistency. There are two fundamentally different ways an interpretation may be reached with only a rather low level of activation; one is simply insufficient evidence, the other is contradictory evidence. It will be clear that the latter type may indeed be reduced to consistency: both inhibitory and excitatory constraints for one or more interpretations are activated, resulting in indeterminacy. For the former type - a low level of activation because the evidence seems to be insufficient one might think of 'vague' utterances, that just do not say very much, in a context that is not very specific either. So "Take the beam bearing first" in a situation where one cannot know which bearing is the beamiest, might be a case in point.

However, even in cases that look like 'vagueness' there may actually be more inconsistency than is initially apparent. Consider the knowledge of Hutchins's observer, in the group version of the bearing taking task, who is to take two bearings. If he (call him: observer A) knows no more than that, and he receives the above instruction, there is actually no logical problem for him to arrive at an interpretation: of two bearings that do not have exactly the same direction, there can be no doubt which one is "the beam bearing". The fact that the problem nevertheless arises in practice, is due to observer A knowing more than that. He knows that there is another observer $B$ on the other wing of the ship who too is to take a bearing, but observer A cannot see this third landmark, so he cannot compare its properties, especially its direction, to those of the landmarks he is to observe himself. It is only because of the knowledge that an unidentified landmark exists, that the identifiability constraint invoked by the definite article "the" does not determine a unique interpretation. So it seems that even this situation is to be construed as one of inconsistency: the use of the definite article is inconsistent with a situation with elements in a set about which nothing is known but that they exist. One might want to argue, in itself correctly, that this situation is characterized by lack of evidence, resulting in indeterminacy of interpretation, and therefore different 
from other situations in which there is conflicting evidence, while here we have a conflict between evidence and knowledge in long term memory; in terms of constraint satisfaction, however, there need not be an essential difference between the two (cf. the previous section).

In any case, vagueness and indeterminacy are real phenomena, although dependent on other relevant knowledge an interpreter might have. Their evaluation thus requires the choice of a particular perspective. For example, one has to know things, or at least make assumptions about the knowledge of the reader of a text in order to determine whether the presence of phrases like As a solution or Therefore raises the level of activation of a certain interpretation beyond the threshold level, or at least strengthens it noticeably (which would lead to a positive evaluation), or whether it is just highly redundant (cf. note 21). But it is clear that at least the analytical part of the work can be described adequately in terms of constraint satisfaction.

This holds even stronger for the issue of consistency. Recall the example of the use of passive constructions in two different Dutch newspapers, Het Parool and $\mathrm{NRC}$ Handelsblad (see pp.18-19). In saying that the use of the passive in NRC is adequate, we actually claim that it is consistent with other data, other things we know that are relevant for our interpretation; in conjunction with other constraints, the use of the passive contributes positively to the interpretation. Contrast this with the following: a local newspaper once reported a match of the town's volleyball team with them frequently in the position of the implicit or explicit agent of passive clauses. This we may call less adequate, precisely because this use is not consistent with other evidence concerning the relation between the producer of the discourse and the agent. Here the description of the pattern of activation and its evaluation are actually closely related activities. As it turns out, it is no coincidence that the pictures given in figure 2 (of evaluation) and in figure 4 (of interpretation), exhibit a highly similar structure: in both cases a number of different inputs jointly gives rise to a new cognitive state. The only difference is that in the former we classified the inputs into two types (given the topic of the discussion), while the latter is a very general schema that does not contain any classification of inputs.

In fact, I want to take this resemblance one step further. I just described an important type of evaluation as an analysis of the degree of consistency between some linguistic constraint and other (linguistic or non-linguistic) constraints (the degree to which these all jointly determine a sensible interpretation) on a specific occasion. But when we formulate the meaning of a linguistic element, we formulate a generalization over the interpretations to which it contributes positively, i.e. features of contexts where the use of this element is consistent. ${ }^{22}$ After all, this is how meanings (the constraints with their weights and directions) arise: through the 
observation of repeated uses of an element and the cumulative adaptation of the connections between input and interpretation resulting from this repetition, the unit involved comes to represent a particular feature as a generalization over a maximum of these contexts.

Interestingly, the conclusion can therefore be that the processes of evaluation (and interpretation), and those of semantic description do not so much differ as to their nature, but rather to their purpose and level of application. An evaluation is a statement about the consistency of something used on a particular occasion, its purpose being to make someone see a mistake, to give a judgment, or to effect a change in usage. A semantic description is a general statement of the same type, i.e. a statement of the kind of interpretations that an element is consistent with, with purposes such as justifying particular statements of the first type, to teach someone the proper use of the language, and things like that.

\section{Conclusion}

I have been asking questions and making claims on the contents of our notions of 'meaning' and 'context', starting from the observation that some seemingly ordinary statements involving these notions turn out, on close inspection, to contradict each other. The background of the discussion was formed by the idea that linguistic theory should provide instruments that can be put to use for relevant purposes outside the domain of linguistics itself. I have tried to systematically approach the relevant questions both from the perspectives of evaluating linguistic usage, and describing it. Now what have we learned from all this? Let me summarize some major points.

1) Evaluative statements on specific instances of linguistic usage presuppose knowledge of the functional properties of the formulations involved. Consequently, distinguishing non-linguistic aspects of situations for the purpose of such evaluations is constrained (not exhaustively determined) by the properties of the linguistic elements.

2) In order to fulfil the justifying role they are supposed to play, statements of these properties must extend beyond the specific usage event under evaluation, and in that sense be context-independent. If the term 'meaning' is used for these properties, it should be limited to this usage, and not be used for referring to elements of a specific interpretation on a particular occasion.

3) In order for such statements to be used in evaluations of specific events, they must at the same time be context-sensitive. Useful context-independent formulations of functional properties of linguistic elements will often contain variables whose value can only be determined upon interpretation. 
4) Both evaluation, interpretation and semantic analysis can be consistently described in terms of a constraint satisfaction model, such that

- meanings are not parts of interpretations, but constraints on them,

- context is manifested in other (linguistic and/or non-linguistic) constraints on interpretations, they do not make meanings (linguistic constraints) change from one situation to another, but may have the effect of enforcing an interpretation in which the (in itself unaltered) constraint invoked by a linguistic element does not play a role, or has in fact a negative value

\section{Notes}

1 Another useful text for grasping the complexities involved in (interrelated) theoretical explications of 'meaning' and 'context', as well as related notions like 'interpretation' and 'function', is Chapter 1 of Levinson (1983)

2 The usefulness of such an idea, in my view, is twofold First, it provides certain linguistic practices with a sound scientific basis Second, it provides linguistics with an independent domain of empirical considerations, to the extent that an analysis turns out to be useful, it derives empirical support from that fact See Verhagen (1992) for an example

3 The logic of the above argument is transferable to such situations, though Formulated abstractly The choice of functional distinctions must be constramed by distinctions between textual features that can be established independently, and to which the functional distinction can be systematically related

4 Note that for the purposes of this paper, I employ a notion of "function" that does not include "Inguistic function" in phrases of the type "The function of linguistic form $Y$ is to X" Including this would clearly lead to vacuousness in statements of the type "If the function of communication is to $X$, the use of $Y$ is appropriate "The notion of "function" that one must have in mind for evaluative purposes is some effect of communication that is intended or assumed on the basis of knowledge of the communicative situation and the actors in it, $1 \mathrm{e}$ on the basis of knowledge of the context This is the reason why I talk about functions here "as aspects of contexts" Consequently, the terms are more or less interchangeable here, usually "context" seems to be the more appropriate term in evaluation ("How appropriate is formulation $Y$ in context $X$ "), while "function" fits better into advice ("When your goal is to perform function $X$, (do not) use $Y$ ")

5 Cf Verhagen 1992 It may actually be better not to consider the latter type as a passive construction at all This is especially true for purposes of evaluation, which, incidentally, demonstrates the co-dependence of the selection of linguistic distinctions on the purposes for which they are used (something I will argue for in general in section 3) There are also analytical and historical arguments not to consider the constructions with $z y n$ as passives, cf Comelıs \& Verhagen (1995)

6 For a more detailed discussion of differences between passives in English and in Dutch, see Cornelis (1996)

7 And perhaps, sufficiently unlike the situations in which a competing linguistic element was used, in case there was a possibility of ambiguity, or an issue of "choosing the right word' in some other sense

8 But, in this case, also a professional like John Searle See Searle (1979), and the discussion in Verhagen (1986), on which the following paragraphs are based

9 Still, a justification for this claim may be called for, I try to undertake such a justification in Verhagen 1995 
10 It is at points like this, I believe, that very fundamental choices of an often ideological nature, inevitably enter the prcture As I mentioned at the end of section 1, I favor an instrumental view of science, for which it is important that the problems to be solved are partly independent from the theories used But a linguist who does not adhere to such a view, or for whom evaluation never constitutes an interesting problem, does not have to be convinced by these considerations at all, of course

11 Does that not make it unintelligible that children learn to use 'simple' structures, e g everyday words and simple clauses, before 'more complex' ones, such as specialized words and subordinated clauses? No, it does not The reason is that the children do not learn a new, more complex expression for communicating something that they already can easily communicate otherwise Quite the contrary learning the advanced skills $i s$, sımultaneously, learning to perform the related communicatıve task Minımally, in learning such advanced skills one acquires the means for doing things straightforwardly that previously required a great deal of effort, or were just too complex to accomplish $\mathrm{A}$ comparison with learning to use a tool may be helpful here When one learns to operate a new tool, enabling oneself to perform a task previously out of range, the report hat one has learned to use a more complex tool does not really give an adequate account of the development of one's skills, the report that one has learned to perform a more complex task, using a new tool, provides a better picture It makes sense, therefore, to say that the acquisition of the ability to use such things as specialized lexicon and subordination, permits a simplification of the cognitive tasks in communicating, and in fact may bring certain tasks within performance range for the first time In short children do not so much learn more complex language, they learn to perform more complex cognitive tasks (using language) In evaluatıng claims about complexity, one should always be careful to look for the standard of comparison in the right place

12 Lakoff (1990) suggests that abstract topological properties are always preserved across domains in a metaphorical mapping, which would look like a true context-independent constraint (the so-called Invariance Hypothesis) As Lakoff indicates at the end of his paper, however, it is not yet clear how this hypothesis is to be construed As preservation of the topological structure of the source domain? That cannot be the case even in view of such simple metaphors as My father is a crab (Turner 1990) Taking it as the requirement of preservation of structure in the target domain, as Turner proposes, seems troublesome to me in view of the fact that for some domains there are no non-metaphonical conceptualizations It might be that an attempt to state precisely what topological properties are (as required by Brugman 1990), will reveal no more than a redefinition of metaphor (some structure has to be mapped, after all, for calling anything a metaphor), making the hypothesis a property of our notion of metaphor rather than a new empirical claim about a mechanism of the mind

13 For another demonstration that this phenomenon is not structural, consider the fact that with another target domain, such features can be activated For example, in 1995 the BBC broadcasted a documentary series called "The death of Yugoslavia"

14 A general introduction into connectionism is Rumelhart (1989), a brief, general comment on connectionism and language is Rumelhart (1988), while Elman (1991) gives an approach to syntax (though definitely not the only one in existence within the connectionist community) Sharkey (1992) is a volume of connectionist papers on a variety of linguistic issues An interesting view on connectionism from a linguistic point of view is provided in section 123 (pp 525-536) of Langacker (1991) For interpretation as constraint satisfaction, see especially Hutchins (1995 240ff), which has also been inspirational for other parts of this paper 
15 For general arguments see the references mentioned in the previous footnote In linguistic processing, a possible test case seems to be the question whether pragmatic inferences, implicatures and the like, are produced after computation of the assumed truth-conditional meanıng, which would favor a rather strict modular view, or computed simultaneously, which would favor a more parallel view Psycholingustic evidence as provided in Lundquist \& Jarvella (1994) in my opınıon points into the latter direction For an opposite view, see Moeschler (1992)

16 There will be more constraints, to other interpretations as well as mutual ones, but they are not really relevant to my present argument, so I leave that out for simplicity sake

17 For example, figure 4 depicts only one constraint per unit, and for no more than one interpretation, whereas an interpretation can actually be better thought of as a set of positively connected units (cf Rumelhart 1989, Hutchins 1995 244/5), and units have multiple connections to several other units (thus aspects of interpretations) It is only III such more realistic elaborations that one can see how a phenomenon like, for example, polysemy may arise in a network But the minimal picture of figure 4 suffices for what I want to argue here

18 Note that one would have a hard time trying to distınguish the ordinary situation as meaningful and this one as meaningless in terms of lack of intention to produce "red" in the latter case traffic lights usually operate automatically

19 Strictly computationally, the solution of the problem might seem transparent The observer with two bearings to take can see for himself which of the two is the beamiest, and he can take it simultaneously with the one bearing taken by his colleague (assuming some means of coordinating the timing of observations) However, this is misleading, for it does not take into account that the bearing information must be propagated through a socialcognitive system, and thus must be reported for further processing by someone else The simple "rule of thumb" as it is applied does not differentıate the taking of the bearing in a strict sense and reporting it, while decoupling these two processes precisely turns out to be a necessary condition for a practicable solution in this type of situation (see Hutchins 1995 206-219 for detalls)

20 This is not to deny that the distinction might be made on other grounds, only that the notion 'extra-linguistic factors' is not going to do the job

21 It is perhaps worthwhile to note that this approach also allows for a fourth, derived, type of evaluation, complementary to consistency, viz degree of redundancy Given a certain number of constraints the strength of an interpretation may become so high that addition of another constraint, although consistent, does not actually increase its strength (in connectionist models, activation functions define sigmord curves, thus implementing the idea of a natural maximum level of activation) The entire situation should then in fact be evaluated negatively too, not because of inconsistency but because the extra processing load does not 'pay off'

22 Note that one should not say "the contexts in which it occurs", precisely because in some contexts a linguistic element may not contribute, or contribute negatıvely to the interpretation, such interpretations cannot be justified by referring to the presence of this particular linguistic element 


\section{References}

Acket, J M , \& Stutterheım, C F P (1960), Stylstudie en styloefentng Haarlem Bohn (11th, revised edition, edited by C F P Stutterheim, first printed 1908)

Bolinger, D (1980), Language - The Loaded Weapon The use and abuse of language today London/New York Longman

Brugman, C (1990), What is the Invariance Hypothesis? Cognitive Lingulstics 1, 257-266

Chilton, P \& Lakoff, G (1989), Foreign policy by metaphor CRL Newsletter, 3/5, 5-19 (Center for Research in Language, University of Calıfornia at San Diego)

Cornelis, L H (1995), Passief en polyphonie Tydschrift voor taalbeheersing 17, 44-54

Cornelis, L H (1996), English and Dutch the passive difference Language Sciences 18, 247-264

Cornelis L H (1997), Passive and perspectvve Amsterdam/Atlanta Rodopı

Cornelıs, L \& Verhagen, A (1995), Does Dutch really have a passıve? In M den Dikken \& K Hengeveld (eds), Linguistics in the Netherlands 1995 Amsterdam/Phıladelphia John Benjamıns, 49-60

Elman, J L (1991), Distributed representatıons, Simple Recurrent Networks, and Grammatical Structure In Machine Learning, 7, 195-225

Hutchins, E (1995), Cognition in the Wild Cambridge, Mass The MIT Press

Jansen, C J M (1995), Rekenen met taal Intreerede TU Eindhoven

Jong, M de (1995), Metaforen en milieubele1d Unpublished paper Utrecht University

Kemmer, S \& Verhagen, A (1994), The grammar of causatives and the conceptual structure of events Cognttive Linguistics 5, 115-156

Lakoff, G (1987), Women, Fire, and Dangerous Things What Categories Reveal about the Mind Chicago University of Chicago Press

Lakoff, G (1990), The Invariance Hypothesis is abstract reasoning based on image-schemas? Cognitive Lingulstics, 1, 39-74

Lakoff, G (1991), Metaphor and war the metaphorical system used to justıfy war in the Gulf Peace Research, 23, 25-32

Lakoff, G \& Johnson, M (1980), Metaphors we live by Chicago/London The University of Chicago Press

Lammerts, A \& Verhagen, A (1994), De oorlog in de krant In A Maes, P van Hauwermerren, L van Waes (red), Perspectieven in taalbeheersingsonderzoek Dordrecht ICG Publications, 375-384

Langacker, R W (1987), Foundations of Cognittve Grammar Volume I Theoretical Prerequisites Stanford, CA Stanford University Press

Langacker, R W (1991), Foundations of Cognitive Grammar Volume II Descriptive Application Stanford, CA Stanford University Press

Levinson, S C (1983), Pragmatics Cambridge Cambridge Unıversity Press

Lundquist, L \& R J Jarvella (1994), Ups and Downs in Scalar Inferences Journal of Semantics, $11,33-53$

Lyons, J (1977), Semantics Volume 2 Cambridge, etc Cambridge University Press 
Moeschler, J (1992), The Pragmatic Aspects of Linguistıc Negation Speech Act, Argumentation and Pragmatic Inference Argumentation 6, 51-76

Maureau, J H (1983), Goed en begrypelyk schriven een analyse van 40 jaar schriffadviezen Muiderberg Coutınho ${ }^{2}$

Ortony, Andrew (ed ) (1979), Metaphor and Thought Cambridge Cambridge University Press [Second, revised edition 1993]

Petrič, I (1992), Here is the news Predictıng listening performance for news texts Dissertation Utrecht University

Reddy, M J (1979), The Conduit Metaphor - A case of frame conflict in our language about language In Ortony (ed ), 1979, 284-324

Reichlıng, A (1967), Het woord Een studle omtrent de grondslag van taal en taalgebruk Zwolle Tjeenk Willink [Second unrevised edition, first edition 1935]

Rumelhart, D E (1979), Some problems with the notion of literal meanings In Ortony (ed), (1979), 78-90

Rumelhart, D E (1988), The connectionist approach to language In Papers and Reports on Child Language Development, 27, 168-174

Rumelhart, DE (1989), The Architecture of Mind A Connectionist Approach In Michael I Posner (ed ), Foundations of Cognttive Sctence Cambridge, MA/London The MIT Press, 133-159

Sharkey, N (ed ) (1992), Connectionist Natural Language Processing Readings from Connection Science Dordrecht, etc Kluwer Academic Publishers

Searle, J R (1979), Metaphor In Ortony (ed ), 1979, 92-123

Turner, M (1990), Aspects of the Invariance Hypothesis Cognitive Lingulistics, 1, 247-255

Veer, A M van der (1994), De troonrede vaag? Dat is de vraag' Unpublıshed paper Utrecht Unıversity

Verhagen, A (1986), Betekenıs en begrıp in beeldspraak, alınea-opbouw en intonatıe Voortgang, $7,25-47$

Verhagen, A (1992), Praxis of linguistics Passives in Dutch Cognitive Linguistics, 3, 301-342

Verhagen A (1995), Subjectification, syntax, and communication In D Stein \& S Wright (eds), Subjectivity and Subjectivisation Linguistic Perspectives Cambridge Cambridge University Press, 103-128

\section{About the author}

Arie Verhagen is associate professor of text linguistics at the Centre for Language and Communication of Utrecht University (department of Dutch Language and Literature) His main research interests are in the area of the relation between grammar and discourse, and cognitive linguistics 